\title{
An Empirical Study on the Public Recognition of "First-Treatment in the Community Hospital" Based on the Hierarchical Diagnosis System in Tianjin
}

\author{
Yueying Liang \\ Graduate school \\ Tianjin University of Traditional Chinese Medicine \\ Tianjin, China \\ m15222752130@163.com
}

\author{
Jian Zhang* \\ School of management \\ Tianjin University of Traditional Chinese Medicine \\ Tianjin, China \\ zjian619@126.com \\ *Corresponding author
}

\begin{abstract}
In recent years, more and more people in Tianjin will not consider the priority of disease and choose to go to large scale polyclinic for medical treatment, so there is a phenomenon that large scale polyclinic are overcrowded while community hospitals are empty. The aim of this study was to solve the problem of difficult medical services in Tianjin. We obtained data through survey and used EXCEL software for data summary, and then used SPSS 20.0 software to perform frequency analysis and chi-square test. The results we obtained demonstrate that the main factors affecting Tianjin residents' recognition of the principle of "first-treatment in the community hospital" include three aspects: policy system, medical level and psychological factors of residents. The innovation of this paper is to investigate the factors affecting residents' recognition of "firsttreatment in the community hospital" through paper questionnaires and online questionnaires, and make suggestions to solve real problems.
\end{abstract}

Keywords-Hierarchical Diagnosis and Treatment System; First-Treatment in the Community; Recognition Degree; Tianjin

\section{INTRODUCTION}

\section{A. Background}

1) The Hierarchical Diagnosis System mentioned in this paper refers to grading according to the severity of the disease and the difficulty of treatment. Different levels of medical institutions are responsible for the treatment of different diseases, and gradually realize the medical process from general to specialize.

2) Felson et al. (1978) [1] considered that "patient-centered medical institutions" adopted a multidisciplinary approach that provided comprehensive, long-term medical services with better medical outcomes.

3)Wilkin D (2002) [2] explored the National Health System of the UK, showing that as early as 1948, the UK implemented a hierarchical diagnosis and treatment System, dividing medical institutions into three levels, and primary medical institutions provided some prevention, treatment and Health care services.

4) Foreign scholars Dupuits et al. (1998) [3] found that only about $5 \%$ of patients seek expert diagnosis and treatment, and more than $90 \%$ of patients can obtain satisfactory medical services from trained family doctors. Therefore, increasing the number of general practitioners is critical to solving the problem of difficult medical services.

5) Amelung et al. (2012) [4] explored the comprehensive development of Germany and concluded that the biggest feature of the medical service system is to separate the outpatient department from the inpatient department, that is, outpatient services are carried out in community primary hospitals, such as ENT registration services. And large hospitals provide inpatient services.

6) S. Inoue et al. (2016) [5] conducted a study on Japan's hierarchical diagnosis system, which showed that community governments should also establish a more complete and strict management system for medical and health services. On the one hand, we must prevent the waste of medical expenses, so as to ensure the full and rational use of primary health resources.

7) In China, due to the prominent problem of "difficulty in seeing a doctor", many scholars have realized that the hierarchical diagnosis system plays an important role in alleviating the problem of difficult medical services and put forward their own opinions and suggestions. Yang Liu (2009) [6] and others believe that the primary health care system is an important way to solve the problem of difficult medical services. One of the most important reasons for the ineffective implementation of China's primary health care system is the weak service capacity of the primary health care system. Zhang zou (2014) [7] believes that "first-treatment in the community hospital" can facilitate residents to seek medical treatment and reduce medical expenses. It also can allocate funds reasonably and improve community service capabilities. Zhang Fangyu (2017) [8] summarized the problems in the classification and 
treatment of Qinghai Province and believed that the hierarchical diagnosis system plays a very important role in solving the problem of uneven distribution of medical and health resources in China. Wei Biyou (2017) [9] proposed the preconditions, implementation conditions and main ways to construct the hierarchical diagnosis system. Wang Min (2017) [10] believed that the implementation of the hierarchical diagnosis system should adopt measures, such as continuous publicity, creation of external conditions, and adjustment of the benefit distribution mechanism.

\section{What is already known about the topic?}

- Foreign scholars have conducted in-depth research on the functional positioning of the graded diagnosis and treatment system. And more domestic scholars' research stays in the concept and theoretical research of the hierarchical diagnosis system. This paper discusses the implementation of the principle of "first-treatment in the community hospital". However, due to differences in cultural differences and research perspectives, previous scholars have not investigated the acceptance of the "first-treatment in the community hospital", thus providing space research for this paper.

\section{What does this paper add?}

- Based on the previous theoretical research, this paper will use the literature research method, questionnaire survey method and data analysis method to find factors affecting the public's recognition of the principle of "first-treatment in the community hospital". From the perspective of influencing factors, this paper puts forward some suggestions on how to improve the residents' acceptance of the principle of "firsttreatment in the community hospital" in Tianjin.

\section{B. Sample and setting}

A questionnaire study was designed. The survey obtained data by distributing paper questionnaires and online questionnaires to residents in Tianjin.

\section{Measuring instrument}

The data collected in this paper were processed by statistical software SPSS 20.0, and the statistical methods adopted mainly included frequency analysis and chi-square test.

TABLE I. BASIC INFORMATION

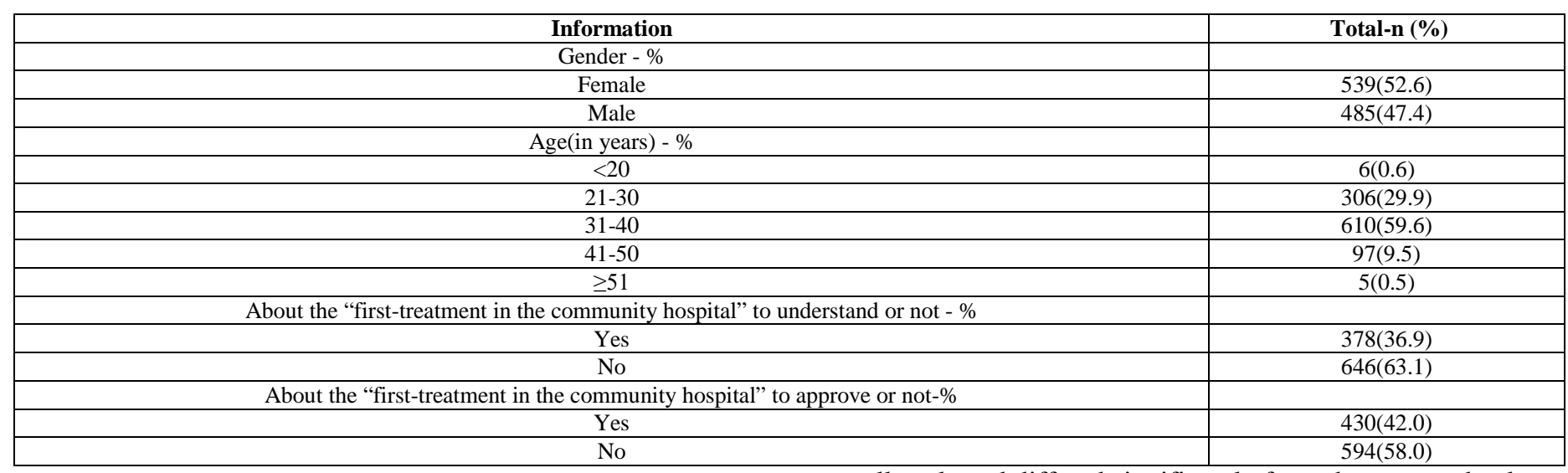

\section{RESUltS}

\section{A. Participants}

A total of 1152 questionnaires were distributed in this survey, and 1024 effective questionnaires were recovered, with an effective rate of about $88.9 \%$. There were 485 males and 539 females among them. And the proportion of males and females was relatively coordinated. Participants aged 31-40, accounting for $59.57 \%$ of the total number, which is the highest proportion. The types of medical insurance of respondents were mainly self-funded, accounting for $32.71 \%$ of the total number, followed by urban medical insurance, accounting for $32.13 \%$ of the total number.

\section{B. Results analysis}

Cross-analysis of the principle of "first-treatment in the community hospital" and they will choose the principle of "first-treatment in the community hospital". The chi-square value is 1049.178 , and the progressive significance is 0.000 , $\mathrm{P}<0.05$. The frequency at which the two questions were actually selected differed significantly from the expected value, indicating whether residents understand that the principle of "first-treatment in the community hospital" has an impact on whether or not to choose initial treatment in the community hospital. Results show that residents who understand the principle of "first-treatment in the community hospital" will go to the community hospital for initial diagnosis, but those who do not understand the principle of "first-treatment in the community hospital" will not go to the community hospital for diagnosis.

TABLE II. CROSS ANALYSIS

\begin{tabular}{|c|c|c|c|c|}
\hline & & \multicolumn{2}{|c|}{$\begin{array}{l}\text { Do you understand "first- } \\
\text { treatment in the community } \\
\text { hospital "? }\end{array}$} & \multirow[t]{2}{*}{ Total } \\
\hline & & Yes & No & \\
\hline \multirow{2}{*}{$\begin{array}{l}\text { Do you choose "first- } \\
\text { treatment in the } \\
\text { community hospital "? }\end{array}$} & Yes & 365 & 65 & 430 \\
\hline & No & 13 & 581 & 594 \\
\hline \multicolumn{2}{|l|}{ Pearson Chi-Square } & \multicolumn{3}{|c|}{$1049.178^{\mathrm{a}}$} \\
\hline \multicolumn{2}{|l|}{ Asymp.Sig. } & \multicolumn{3}{|c|}{.000} \\
\hline
\end{tabular}


According to the questionnaire in the second part of the screening information, 430 people said that they would choose primary hospital (including township hospitals, village clinics, community hospitals, etc.) to have an initial diagnosis. Through investigation of the cause, it was found that most people think that primary hospitals can meet their basic medical needs without having to go to large scale polyclinic.

TABLE III. CHI-SQUARE TEST OF CAUSES

The chi-square test was used to determine the reason why patients chose "primary diagnosis"

\begin{tabular}{|c|c|c|c|c|c|}
\hline Factors & $\mathrm{N}$ & $\mathrm{NO}$ & YES & Chi-Square & Asymp.Sig. \\
\hline \multirow{2}{*}{$\begin{array}{l}\text { Pay less and reduce the burden of } \\
\text { patients }\end{array}$} & Observed N & 270 & 160 & $28.140^{\mathrm{a}}$ & .000 \\
\hline & Expected N & 164.7 & 164.7 & & \\
\hline \multirow{2}{*}{ To meet basic medical needs } & Observed N & 115 & 315 & $93.023^{\mathrm{a}}$ & .000 \\
\hline & Expected N & 164.7 & 164.7 & & \\
\hline \multirow{2}{*}{$\begin{array}{l}\text { Near home and convenient for } \\
\text { medical treatment }\end{array}$} & Observed N & 251 & 179 & $12.056^{\mathrm{a}}$ & .001 \\
\hline & Expected N & 164.7 & 164.7 & & \\
\hline \multirow{2}{*}{ Familiar with physicians } & Observed N & 254 & 176 & $14.149^{\mathrm{a}}$ & .000 \\
\hline & Expected N & 164.7 & 164.7 & & \\
\hline \multirow{2}{*}{ Medical insurance policy guidance } & Observed N & 278 & 152 & $36.921^{\mathrm{a}}$ & .000 \\
\hline & Expected N & 164.7 & 164.7 & & \\
\hline
\end{tabular}

According to the screening information in the second part of the questionnaire, 594 people said that they would not choose to go to the primary hospital (including township hospitals, village clinics and community hospitals) for initial dialogue when they were sick. When asked about the reasons, $65.99 \%$ of the respondents thought that the health conditions of community hospitals were not good enough, and $62.63 \%$ of the respondents thought that the types of medicines in community hospitals were incomplete. $40.40 \%$ of people thought that they are used to going to large hospitals for medical treatment. $30.47 \%$ of people thought that doctors' medical treatment is not high enough, $24.24 \%$ of people thought that departments are incomplete, and $17.85 \%$ of them thought that medical equipment is not advanced. So, it can be found that the most important factor determining whether residents are willing to go to the primary hospital for initial dialogue is the condition of the medical institution.

TABLE IV. CAUSE INVESTIGATION 1

\begin{tabular}{|c|c|c|c|}
\hline \multicolumn{4}{|c|}{ Reasons why patients do not choose " first-treatment in the community hospital" } \\
\hline \multirow{9}{*}{ Valid } & Factors & Frequency & Percent \\
\hline & Doctors are not good enough & 181 & $30.47 \%$ \\
\hline & Health facilities have poor sanitation & 392 & $65.99 \%$ \\
\hline & The medical equipment is not advanced & 106 & $17.1785 \%$ \\
\hline & There are not all kinds of medicines & 372 & $62.63 \%$ \\
\hline & The department setting is not complete & 144 & $24.24 \%$ \\
\hline & It is close to a big hospital & 240 & $40.40 \%$ \\
\hline & Others & 2 & $0.34 \%$ \\
\hline & Total & 594 & $100 \%$ \\
\hline
\end{tabular}

When asked why it is difficult for the primary medical institutions to implement the "first-treatment in the community hospital". $73.57 \%$ of the respondents believe that there is a lack of outpatient medical insurance support. $47.81 \%$ of the respondents are subjectively unacceptable. With $42.9 \%$ of respondents believe that the residents' recognition of community hospital doctors is not high.

TABLE V. CAUSE INVESTIGATION 2

\begin{tabular}{|c|c|c|c|}
\hline \multicolumn{3}{|c|}{ Reasons why it is difficult to carry out " first-treatment in the community hospital " } \\
\hline \multirow{4}{*}{ Valid } & Factors & Frequency & Percent \\
\cline { 2 - 4 } & People refused to & 284 & $47.81 \%$ \\
\cline { 2 - 4 } & Lack of outpatient health care support & 437 & $73.57 \%$ \\
\cline { 2 - 4 } & A shortage of GPS & 169 & $28.45 \%$ \\
\cline { 2 - 4 } & Lack of trust in primary care doctors & 250 & $42.09 \%$ \\
\cline { 2 - 4 } & The residents lack medical knowledge & 178 & $29.97 \%$ \\
\cline { 2 - 4 } & Rural floating population policy impact & 137 & $23.06 \%$ \\
\cline { 2 - 4 } & Others & 3 & $0.51 \%$ \\
\cline { 2 - 4 } & Total & 594 & $100.00 \%$ \\
\hline
\end{tabular}

\section{DISCUSSION}

\section{A. Policy system}

From a policy perspective, the government health management department's assistance to primary health care institutions will increase residents' acceptance of "firsttreatment in the community hospital", especially in the medical security system. Therefore, the government health management department can reduce the patient's self-pay quota by increasing the proportion of medical insurance reimbursement when residents see a doctor in a community hospital. From the survey data, the level of medical expenses has a great impact on patients' choice of medical care. 
Second, the residents subjectively refused. The last reason is that the level of primary care is not high. According to the above survey results, there are three main factors affecting the public's acceptance of the principle of "first-treatment in the community hospital”: policy system, medical level and residents' psychological factors.

\section{ACKNOWLEDGMENT}

We would like to express our heartfelt thanks to all those who participated in the questionnaire.

\section{REFERENCES}

[1] Felson, M, Spaeth, J.L., Community Structure and Collaborative Consumption: A Routine Activity Approach .J. American Behavioral Scientist. 1978.21(4):23.

[2] Wilkin, D., Primary care budget holding in the United Kingdom National Health Service: learning from a decade of health service reform .J. Medical journal of Australia. 2002.176 (11):539-542.

[3] Dupuits,F.M.H.M, Hasman, A. Pop, P., Computer-based assistance in family medicine .J. Computer Methods \& Programs in Biomedicine. 1998.55(1):39-50.

[4] Amelung,V.Hildebrandt, H. Wolf, S., Integrated care in Germany-a stony but necessary road. J. International Journal of Integrated Care. 2012.12(1):e16.

[5] S. Inoue, H. Xu, J. Maswana, et al., Construction of System Dynamics Model for Medical Care System of Japan. J. Value in Health. 2016.19(7).

[6] Yang, L., Li, W., Feng Z.D., The impact of primary health service capacity on the first consultation system. Chinese J. Medicine and Philosophy. 2009. (15):43-44. 47. (In Chinese)

[7] Zhang, Z., Sun, J., Zhang, X.T., Analysis on the utilization level of outpatient service in designated primary medical institutions under the community first consultation system. Chinese J. Electronic test. 2014. (19):118-119,122. (In Chinese)

[8] Zhang, F.Y., Discussion on the classification and treatment system and its significance. Chinese J. Chinese health nutrition. 2017. (24):285-286. (In Chinese)

[9] Wei, B.Y., Research on the status quo and countermeasures of grading diagnosis and treatment system. Chinese J. Comprehensive Health (second edition). 2017. (11):24. (In Chinese)

[10] Wang, M., Yu, G.L., Huang, Y. M., Study on the implementation barriers and coping strategies of grading diagnosis and treatment system. Chinese J. Health economic research. 2017. (4):15-18. (In Chinese) 